\title{
Natural apoptosis in developing mice dopamine midbrain neurons and vermal Purkinje cells
}

\author{
Joaquín Martí-Clúa \\ Departament de Biologia Cellular, de Fisiologia i d'Immunologia, Unidad de Citologia i d'Histologia, Facultat de Biociències, \\ Universitat Autònoma de Barcelona, Barcelona, Spain
}

\begin{abstract}
Natural cell death by apoptosis was studied in two neuronal populations of BALB/C, C57BL/6 and B6CBA-A $A^{W-j} / A$ hybrid stock mice: (I) dopaminergic (DA) neurons in choosing coronal levels throughout the anteroposterior extent of the substantia nigra pars compacta (SNC), and (II) Purkinje cells (PCS) in each vermal lobe of the cerebellar cortex. Mice were collected at postnatal day (P) 2 and P14 for the midbrain study, and at P4 and P7 for the analysis of the cerebellum. No DA cells with morphologic criteria for apoptosis were found. Moreover, when the combination of tyrosine hydroxylase and TUNEL or tyrosine hydroxylase and active caspase-3 immunohistochemistry were performed in the same tissue section, no DA cells TUNEL positives or active caspase-3-stained DA neurons were seen. On the other hand, when PCs were considered, data analysis revealed that more dying PCs were observed at P4 than at P7. Values of neuron death were highest in the central lobe; this was followed by the posterior and anterior lobes and then by the inferior lobe. To determine if apoptotic death of PCS is linked to their time-of-origin profiles, pregnant dams were administered with [ $\left.{ }^{3} H\right]$ TdR on embryonic days 11-12, 12-13, 13-14 and 14-15. When TUNEL and $\left.{ }^{3} H\right] T d R$ autoradiography or active caspase-3 immunohistochemistry and $\left[{ }^{3} H\right] T d R$ autoradiography were combined in the same tissue section, results reveal that the naturally occurring PC death is not related to its time of origin but, rather, is random across age.
\end{abstract}

Key words: postnatal, dopamine, substantia nigra pars compacta, cerebellar cortex, Purkinje cells, neurogenetic timetables, apoptosis.

\section{Introduction}

An important principle of neural development is that cell populations are generated in higher numbers during embryogenesis and undergo a natural cell death that determines their final counts in adults $[7,39]$. When neurons die following a stereotyped series of molecular and cellular events, it is termed apoptosis $[11,18]$. Apoptosis serves for a joint of critical processes including the withdrawal of aberrant axon projection, the elimination of ectopic neurons and the refinement of neural circuits [10]. It has been proposed that excess of neuronal elements is regulated by competition among members of the neuronal population for the trophic support that they receive from their postsynaptic targets and from afferent projections $[3,23,40]$. 
Dopaminergic (DA) neurons of the midbrain are involved in several neurologic and psychiatric diseases including schizophrenia, addictive behaviors and satiety disorders [8,42]. They are especially vulnerable to degeneration in human dopamine deficiency diseases [44]. It has been proposed that an inappropriate amplification of basal physiological cell death in nigrostriatal DA neurons may have an impact on later susceptibility to disorders such as Parkinson's disease [34].

The natural occurring neuron death in the substantia nigra pars compacta (SNc) has been reported in rats [6]. The time course of this phenomenon is largely postnatal, with important roles for glial cell line-derived neurotrophic factor and brain-derived neurotrophic factor $[20,37,38]$. In the striatum, the principal input component of the basal ganglia, apoptotic dying cells occur within the first month of postnatal development [32].

In mice, on the other hand, natural death of SNC DA neurons has been studied with contradictory results. This is because several authors observed evidence of neuroapoptosis during the early postnatal development of this motor nucleus [14], whereas Lieb et al. [22] and Blum [5] did not find any DA neurons with signs of apoptosis. To address this issue, we examined histologically, at $\mathrm{P} 2$ and $\mathrm{P} 14$, series of $B A L B / C, C 57 B L / 6$ and B6CBA-A ${ }^{w-j} / A$ hybrid stock brains for signs of apoptosis in midbrain DA cells at several anatomical levels throughout the anteroposterior axis of the SNc. In the present study, we used the TUNEL method in conjunction with morphological analysis at the light microscopic level, and immunohistochemistry for active caspase-3, aiming to determine and quantify apoptotic neuron death in the SNc during normal development.

In the cerebellar cortex, on the other hand, PCs are also involved in processes of apoptosis $[17,26]$. Two time windows have been reported: in the first of these, apoptotic figures have been found at E15 [2]. In the second, dying PCs are seen from birth until P10 $[16,19,25]$. Thus, whereas the timing and extent of dying PCs have been addressed [16], to our knowledge, no attempts have been made to determine whether physiological PC death is related to its time of origin. We know from previous autoradiographic studies that, in mice, cerebellar PCs are generated according to precise neurogenetic timetables [27,29]. Consequently, terminal deoxynucleotidyl transferasemediated dUTP nick end-labeling method (TUNEL) and $\left[{ }^{3} \mathrm{H}\right] \mathrm{TdR}$ autoradiography, and active caspase-3 immunohistochemistry and $\left[{ }^{3} \mathrm{H}\right] \mathrm{TdR}$ autoradiography were combined in the same tissue section to determine, at P4 and P7, if apoptotic PCs death in the region of the vermis is linked to their time of origin.

\section{Material and methods \\ Animal preparation and experimental design}

$\mathrm{BALB} / \mathrm{c}$ and $\mathrm{C} 57 \mathrm{BL} / 6$ mice were provided by Autonomous University of Barcelona animalarius. B6CBA-A ${ }^{\mathrm{w}-\mathrm{j} / \mathrm{A}}$ hybrid stock mice were obtained from the mouse colony at Indiana University School of Medicine. The experimental animals were the offspring of pregnant dams injected subcutaneously between 8:00 a.m. and 9:00 a.m. on two consecutive days with $\left[{ }^{3} \mathrm{H}\right] \mathrm{TdR}(5 \mu \mathrm{Ci} / \mathrm{g}$ of body weight, New England Nuclear, no. NET-027) according to the following time-window: embryonic day (E)11-12, E12-13, E13-14 and E14-15. For staging of animals, E1 was the day after mating. The day of birth was defined as PO. Seven animals were used for each experimental group and data time point. Standard laboratory conditions (food and water ad lib, $22 \pm 2^{\circ} \mathrm{C}, 12 \mathrm{~h}$ light: dark cycle starting at 08:00) were used and all the experiments were performed in accordance with the Ethical Committee of our University.

Following anesthesia with sodium pentobarbital (50 mg/kg of body weight, i.p.), pups were perfused intracardially with $10 \%$ neutral buffered formalin. Tissue processing was developed as regular procedures from our laboratory. The blocks containing the midbrain and the cerebellum were sectioned at $10 \mu \mathrm{m}$ in coronal and sagittal planes, respectively. Only one of every fifth section was placed on microscopic slides previously coated with poly-(L-lysine).

\section{Immunocytochemistry for tyrosine hydroxylase and TUNEL, and tyrosine hydroxylase and active caspase-3}

Sections were immunostained for tyrosine hydroxylase. They were deparaffinized and rehydrated through a graded series of ethanol and distilled water, as in routine processing. After this, sections were washed twice for $15 \mathrm{~min}$ in PBS, soaked in a solution containing absolute methanol plus 3\% $\mathrm{H}_{2} \mathrm{O}_{2}$ for 20 min. Sections were then washed in PBS, blocked for 30 min with 10\% normal goat serum in PBS, followed by washes with $0.5 \%$ Triton X-100/PBS 
and finally PBS. Afterwards, sections were incubated with a monoclonal mouse anti-tyrosine hydroxylase (1 : 1000, Sigma, St Louis, MO, USA) for $90 \mathrm{~min}$ at room temperature. After rinsing with PBS during $15 \mathrm{~min}$, sections were incubated for $1 \mathrm{~h}$ at room temperature with the secondary antibody (Sigma biotinylated anti mouse IgG diluted 1:300 in PBS) and extravidin-peroxidase (Sigma). Immunoreactive sites were detected by submerging the slides in $0.05 \%$ diaminobenzidine tetrahydrochloride (DAB) plus $3 \%$ $\mathrm{H}_{2} \mathrm{O}_{2}$ in TBS $0.05 \mathrm{M}$ (pH 7.6) supplemented with $2 \mathrm{ml}$ of $\mathrm{CoCl}_{2}(1 \%)$ for $5 \mathrm{~min}$. With this color modification of $\mathrm{DAB}$, we yield a distinct dark-blue color that is easily distinguished from brown DAB [13].

After immunocytochemical evaluation, the slides were processed for TUNEL for visualizing the $3^{\prime}-\mathrm{OH}$ ends of DNA fragments in apoptotic cells or for active caspase-3. For TUNEL, sections were incubated with $20 \mu \mathrm{g} / \mathrm{ml}$ of proteinase $\mathrm{K}$ during $20 \mathrm{~min}$ at room temperature. They were then soaked in the TdT buffer ( $30 \mathrm{mM}$ Tris- $\mathrm{HCl}, \mathrm{pH}$ 7.2, $140 \mathrm{mM}$ sodium cacodylate, $1 \mathrm{mM} \mathrm{CaCl}_{2}$ ) for $15 \mathrm{~min}$ and then incubated at $37^{\circ} \mathrm{C}$ for $75 \mathrm{~min}$ with the TdT buffer containing $0.3 \mathrm{eu} / \mu \mathrm{l}$ terminal deoxynucleotidyl transferase and $0.04 \mathrm{nmol} / \mu \mathrm{l}$ biotin-16-deoxyuridine triphosphate. The reaction was stopped by soaking the sections in Tris buffer. The biotinylated dUTP molecules incorporated into nuclear DNA were visualized by incubation with horseradish peroxidase-conjugated streptavidin (Dako, Glostrup, Denmark) diluted $1: 100$ at $37^{\circ} \mathrm{C}$ for $30 \mathrm{~min}$. After further rinsing of the sections in PBS, the peroxidase coloring reaction was performed by immersing the sections for $5 \mathrm{~min}$ in $0.05 \mathrm{M}$ Tris- $\mathrm{HCl}$ buffer, $\mathrm{pH} 7.4$, containing $30 \mathrm{mg} / \mathrm{dl}$ DAB, $65 \mathrm{mg} / \mathrm{dl}$ sodium azide, $10 \mathrm{mM}$ imidazole, and $0.005 \% \mathrm{H}_{2} \mathrm{O}_{2}$, yielding the characteristic brown color. Sections were counterstained with hematoxylin. For positive control of TUNEL labeling, histological sections were incubated with DNase $(5 \mu \mathrm{g} / \mathrm{ml})$ at $37^{\circ} \mathrm{C}$ during $10 \mathrm{~min}$ to induce DNA strand breaks. For negative control, terminal deoxynucleotidyl transferase was replaced with distilled water.

To immunostain active caspase-3, after TH immunohistochemistry, sections were processed for microwave-mediated antigen retrieval, in $0.01 \mathrm{M}$ citrate buffer (pH 6). Sections were heated at $750 \mathrm{~W}$ for $5 \mathrm{~min}$. They were then cooled for $20 \mathrm{~min}$ at room temperature. Nonspecific binding was blocked for $30 \mathrm{~min}$ with $10 \%$ normal goat serum in PBS containing 0.5\% Triton X-100. Afterwards, sections were incubated in primary antibody to active caspase- 3 (polyclonal rabbit anti-active caspase-3, 1:100; Chemicon International) diluted in PBS and incubated for $75 \mathrm{~min}$ at room temperature. This was followed by rinses with PBS during $15 \mathrm{~min}$. Sections were then incubated for $1 \mathrm{~h}$ at room temperature with the secondary antibody (Sigma biotinylated anti rabbit IgG diluted 1:500 in PBS) and extravidin-peroxidase (Sigma). Slices were treated with $0.05 \%$ DAB plus $3 \% \mathrm{H}_{2} \mathrm{O}_{2}$ in TBS $0.05 \mathrm{M}$ (pH 7.6) for 5 min.

Sections were counterstained with hematoxylin, dehydrated and cover-slipped. The specificity of the antibodies was tested by omission of the primary antibodies.

\section{TUNEL, active caspase-3 \\ immunohistochemistry and $\left[{ }^{3} \mathrm{H}\right] \mathrm{TdR}$ autoradiography}

When TUNEL or active caspase-3 immunohistochemistry had been completed (see previous section), the slides were processed for autoradiography following a previously described method [28]. This consisted of coating the slides with liquid photographic emulsion (undiluted Kodak NTB3) in a darkroom illustrated by Kodak Series 2 dark-red safelights, drying them in a humidified atmosphere, and storing them in light-tight boxes in the refrigerator for an exposure period of 12 weeks. The slides were developed in Kodak D-19, and were then post-stained with hematoxylin, dehydrated, and cover-slipped with Permount. Labeled PCs could be identified by the cluster of reduced silver grains (black granules) over their nuclei. Neurons with ten grains or more per nucleus were considered labeled.

\section{Quantitative analyses}

All of the histological quantifications were performed blindly. Two neuronal populations were studied: the SNc DA neurons and the vermal PCs. DA cells were separately analyzed in plates 46, 50, 54 and 60 along the anteroposterior axis of the SNc $[30,31,43]$. PCs were studied in each cerebellar cortex lobe (anterior, central, posterior and inferior) at the level of the vermis. Their names and boundaries are those assigned by Altman and Bayer [1].

For quantification, a DA neuron was considered as apoptotic only if it fulfilled the morphologic criteria for apoptosis (characteristic basophilic, rounded and intranuclear chromatin clumps) reported previ- 
ously $[15,36]$. On the other hand, to be considered as an apoptotic PC, the structure observed had to fulfill the following criteria: (a) one or more fragments of highly condensed chromatin (within or reminiscent of a pyknotic nucleus) and distinct from the PC nucleolus, and (b) position within the PC layer [16].

Frequency of $\left[{ }^{3} \mathrm{H}\right] \mathrm{TdR}$-labeled PCs was calculated as a percentage by dividing the number of neurons labeled by the total number of neurons scored. To infer PCs neurogenetic timetables, a modification of the progressively delayed comprehensive labeling procedure was used [4]. The rationale of this method is based on the fact that ${ }^{3} \mathrm{H}-\mathrm{TdR}$ will only be incorporated by those neuroblasts engaged in the DNA synthesis during isotope supply. Whether the onset of the injections with the radioactive agent is progressively delayed by 24 hours, the percentage of labeled cells decreases reflecting the production of neurons from their precursor cells. Thus, the proportion of PCs originating between two injection series is equal to the daily decline in the percentage of labeled neurons.

\section{Statistical treatment}

Two-way ANOVAs with "age" and "strain" as the main between-subject factors were used to analyze the number of dying cells as well as the proportion of labeled neurons. When appropriate, further decomposition of the interaction was performed. Levene's test was used to test homogeneity of variances. When necessary, data were log transformed to achieve homogeneity of variances. If only two means were available, Student's t-test or Mann-Whitney $U$ test were utilized. A $p$ value less than 0.05 was considered statistically significant.

\section{Photographic material}

Photographic material presented in this report was digitally captured by a CCD-IRIS color video camera (Sony, Japan) coupled to the microscope. The digitized images were processed with the Adobe Photoshop software.

\section{Results}

\section{Neuroapoptosis in the midbrain}

The gross overall morphology of the SNc appeared similar in BALB/C, C57BL/6 and B6CBA-A ${ }^{\mathrm{w}-\mathrm{j} / \mathrm{A}}$ hybrid stock mice. In order to perform a detailed analysis of

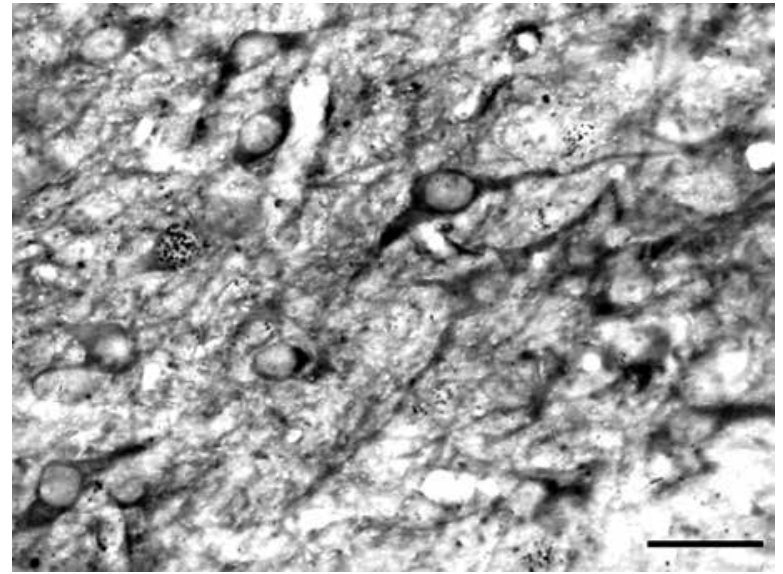

Fig. 1. High-magnification of a TH-immunostained section through the substantia nigra pars compacta of a B6CBA-A ${ }^{w-j} / A$ hybrid stock mouse sacrificed at P14. Scale bar: $50 \mu \mathrm{m}$.

physiological cell death, light microscopic observations of the midbrain were made through the anteroposterior axis of the SNc. After a meticulous study based on an extensive collection of sections, no DA cells with morphologic criteria for apoptosis were seen. When the combination of tyrosine hydroxylase and TUNEL or tyrosine hydroxylase and active caspase-3 immunohistochemistry were performed in the same tissue section, no DA cells TUNEL positives or active caspase-3-stained DA neurons were observed in any level of the studied midbrain. This has been taken into account in all of the examined mice. Figure 1 shows examples of tyrosine hydroxylase-stained neurons in the SNc from B6CBA-Aw-j/A hybrid stock mice.

\section{Purkinje cell death in the cerebellar cortex}

The cerebellum showed the characteristic pattern of fissures and foliar crowns. Cardinal fissures determining the limits among the four lobes of the cerebellar cortex were present and distinguishable. This occurred in all of the studied mice. Apoptotic PCS were confirmed by DNA fragmentation, the TUNEL method or active caspase-3. TUNEL positive macroneurons in the developing cerebellum were selectively labeled among numerous hematoxylin-stained PCs. Dying PCs were distributed throughout the cerebellar cortex lobes at both ages examined. As a secondary marker of apoptosis, selected cerebellar cortex sections were tested for immunore- 
Table I. Number of TUNEL positives Purkinje cells per section in each lobe of the cerebellar cortex

\begin{tabular}{|lccccc|}
\hline Age & Strain & LA & LC & LP & LI \\
\hline P4 & BALB/c & $6.1 \pm 0.9^{*}$ & $12.3 \pm 1.4^{*}$ & $6.5 \pm 0.7$ & $3.8 \pm 0.8^{*}$ \\
\hline P7 & BALB/c & $3.1 \pm 0.8^{*}$ & $4.9 \pm 0.9^{*}$ & $2.2 \pm 0.6^{*}$ & $1.5 \pm 0.9^{*}$ \\
\hline P4 & C57BL/6 & $6.4 \pm 0.9^{*}$ & $11.2 \pm 1.5^{*}$ & $7.4 \pm 0.8^{*}$ & $3.4 \pm 0.5^{*}$ \\
\hline P7 & C57BL/6 & $2.7 \pm 0.7^{*}$ & $4.5 \pm 0.9^{*}$ & $2.6 \pm 0.9^{*}$ & $1.3 \pm 0.6^{*}$ \\
\hline P4 & B6CBA-Aw-j/A hybrid stock & $7.2 \pm 0.8^{*}$ & $11.7 \pm 1.3^{*}$ & $7.0 \pm 0.8^{*}$ & $4.1 \pm 0.5^{*}$ \\
\hline P7 & B6CBA-Aw-j/A hybrid stock & $3.4 \pm 0.7^{*}$ & $5.9 \pm 1.1^{*}$ & $2.3 \pm 0.7^{*}$ & $1.4 \pm 0.5^{*}$ \\
\hline
\end{tabular}

Means \pm S.E.M $(n=7)$ per section are indicated

*Student's t-test or Mann-Whitney U test, $p<0.05$ vs. P4

$P$ - postnatal day, $L A$ - anterior lobe, $L C$ - central lobe, $L P$ - posterior lobe, $L I$ - inferior lobe

Table II. Number of active caspase-3-immunoreactive Purkinje cells per section in each lobe of the cerebellar cortex

\begin{tabular}{|c|c|c|c|c|c|}
\hline Age & Strain & LA & LC & LP & $\mathrm{LI}$ \\
\hline P4 & $\mathrm{BALB} / \mathrm{C}$ & $2.4 \pm 0.4^{*}$ & $5.1 \pm 0.7^{\star}$ & $3.4 \pm 0.5^{\star}$ & $3.4 \pm 0.5^{*}$ \\
\hline P7 & $\mathrm{BALB} / \mathrm{C}$ & $1.6 \pm 0.5^{*}$ & $2.3 \pm 0.4^{\star}$ & $1.5 \pm 0.3^{*}$ & $1.7 \pm 0.4^{*}$ \\
\hline P4 & $\mathrm{C} 57 \mathrm{BL} / 6$ & $2.6 \pm 0.4^{*}$ & $4.7 \pm 0.5^{*}$ & $3.7 \pm 0.4^{*}$ & $3.2 \pm 0.9^{*}$ \\
\hline P7 & $\mathrm{C} 57 \mathrm{BL} / 6$ & $1.3 \pm 0.2^{*}$ & $2.4 \pm 0.4^{*}$ & $1.6 \pm 0.3^{*}$ & $1.6 \pm 0.5^{*}$ \\
\hline P4 & B6CBA-A ${ }^{w-j} / A$ hybrid stock & $2.2 \pm 0.5^{*}$ & $4.5 \pm 0.5^{*}$ & $3.5 \pm 0.4^{*}$ & $3.5 \pm 0.5^{*}$ \\
\hline P7 & B6CBA-A ${ }^{w-j} / A$ hybrid stock & $1.3 \pm 0.5^{*}$ & $2.5 \pm 0.5^{*}$ & $1.6 \pm 0.2^{*}$ & $2.4 \pm 0.3^{*}$ \\
\hline
\end{tabular}

Means \pm S.E.M $(n=7)$ per section are indicated

*Student's t-test or Mann-Whitney U test, $p<0.05$ vs. P4

$P$ - postnatal day, $L A$ - anterior lobe, $L C$ - central lobe, $L P$ - posterior lobe, $L I$ - inferior lobe

activity to activated caspase-3. Immunoreactivity to active caspase- 3 occurred in the PC cytoplasm.

Numbers of TUNEL positive neurons and active caspase-3-reactive PCs quantified at P4 and P7 in the anterior, central, posterior and inferior lobes are presented in Tables I and II. Results of the twoway ANOVA are depicted in Table III. Data analysis demonstrated significant effects of the "age" in all lobes of the cerebellar cortex. No effect of the main factor "strain" was observed. The interaction of "age X strain" was not statistically significant. Post hoc comparisons of means revealed that mice collected at P4 always presented more apoptotic PCs than those killed at P7. Moreover, data analysis indicated that numbers of TUNEL positives and active caspase-3-immnunoreactive PCs were highest in the central lobe; this was followed by the posterior and anterior lobes and then by the inferior lobe.

Developmental timetables of PCs at P4 and P7 were inferred at the four, previously indicated, lobes of the cerebellar cortex. Initially, the frequency of tagged PCs was estimated by sequential $\left[{ }^{3} \mathrm{H}\right] \mathrm{TdR}$ labeling embryonic windows as graphically displayed in Figure 2. Statistical analysis of the results showed that at any given time within this generation period, and both for the P4 and P7, the percentage of labeled PCs remains constant within each lobe studied. In a subsequent analysis, profiles of PCs origin were constructed. In Figure 3, the frequencies of newly generated PCs at each selected lobe are plotted against time. Data analysis indicated that the birth sequences of postmitotic neurons for both survival times within each cerebellar cortex lobe are closely similar. Figure 4 shows examples of PCs labeled with $\left[{ }^{3} \mathrm{H}\right] \mathrm{TdR}$.

\section{Discussion}

\section{Neuron death in the substantia nigra pars compacta}

The physiological loss of SNc DA cells has been convincingly demonstrated in rats [6] and non-hu- 
Table III. Results of the two-way ANOVA of the dying, TUNEL and active caspase-3-reactive Purkinje cells number per section in each lobe of the cerebellar cortex

\begin{tabular}{|c|c|c|c|}
\hline & Dying & TUNEL & Caspase-3 \\
\hline \multicolumn{4}{|c|}{ Anterior lobe } \\
\hline Age (A) & {$\left[F_{1,36}=61.4, p<0.00001\right]$} & {$\left[F_{1,36}=16.6, p<0.0002\right]$} & {$\left[F_{1,36}=12.2, p<0.001\right]$} \\
\hline Strain (S) & NS & NS & NS \\
\hline$A \times S$ & NS & NS & NS \\
\hline \multicolumn{4}{|l|}{ Central lobe } \\
\hline Age (A) & {$\left[F_{1,36}=96.1, p<0.00001\right]$} & {$\left[F_{1,36}=43.8, p<0.00001\right]$} & {$\left[\mathrm{F}_{1,36}=34.6, p<0.00001\right]$} \\
\hline Strain (S) & NS & NS & NS \\
\hline$A \times S$ & NS & NS & NS \\
\hline \multicolumn{4}{|c|}{ Posterior lobe } \\
\hline Age (A) & {$\left[F_{1,36}=92.1, p<0.00001\right]$} & {$\left[F_{1,36}=45.3, p<0.00001\right]$} & {$\left[F_{1,36}=16.8, p<0.001\right]$} \\
\hline Strain (S) & NS & NS & NS \\
\hline$A \times S$ & NS & NS & NS \\
\hline \multicolumn{4}{|l|}{ Inferior lobe } \\
\hline Age (A) & {$\left[F_{1,36}=62.5, p<0.00001\right]$} & {$\left[F_{1,36}=33.4, p<0.00001\right]$} & {$\left[\mathrm{F}_{1,36}=12.51, p<0.001\right]$} \\
\hline Strain (S) & NS & NS & NS \\
\hline$A \times S$ & NS & NS & NS \\
\hline
\end{tabular}

NS- not significant

A

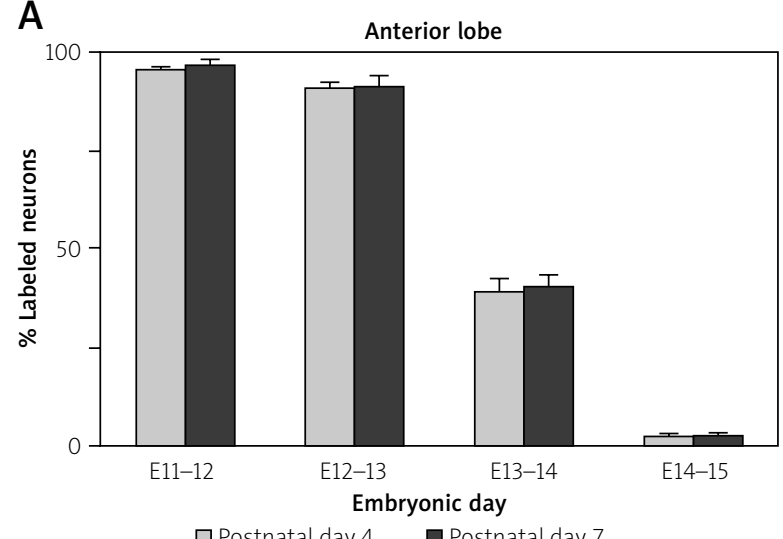

$\square$ Postnatal day $4 \quad \square$ Postnatal day 7

C

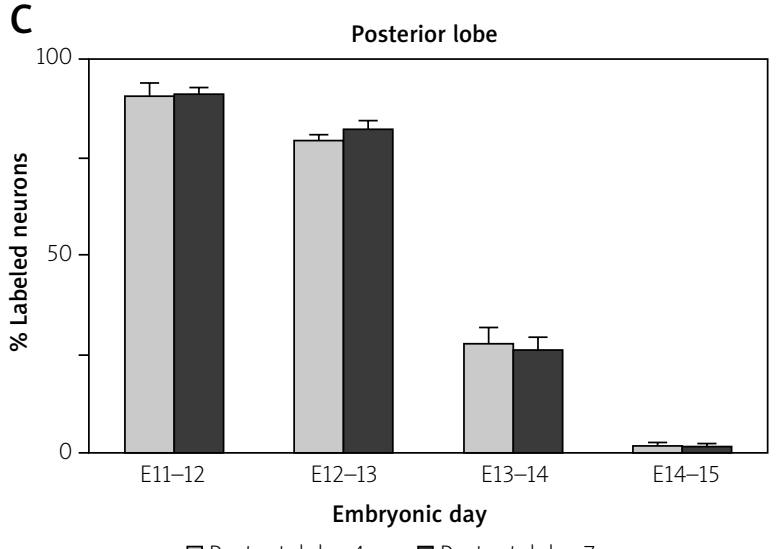

B

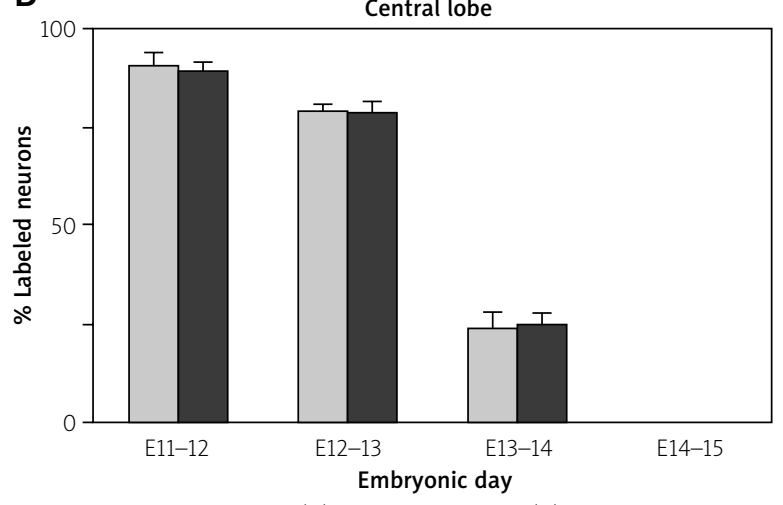

$\square$ Postnatal day $4 \quad \square$ Postnatal day 7

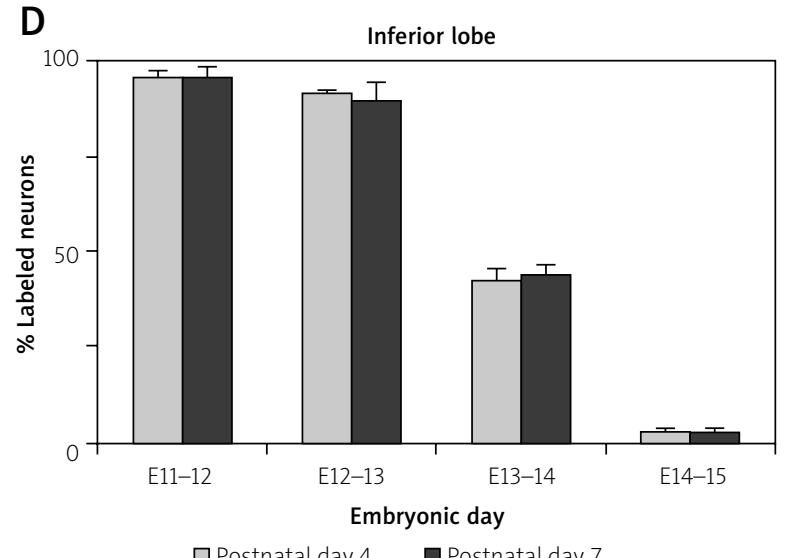

$\square$ Postnatal day 4

$\square$ Postnatal day 4

Postnatal day 7

Fig. 2. Comparison of $\left[{ }^{3} \mathrm{H}\right] \mathrm{TdR}$-labeling patterns in each lobe of the cerebellar cortex. Frequency histograms of Purkinje cells labeled with $\left[{ }^{3} \mathrm{H}\right] \mathrm{TdR}$ on two consecutive days of the embryonic period (abscissa) and survival until P4 (empty columns) and P7 (solid columns). Percentages are expressed as mean \pm SEM. 
A

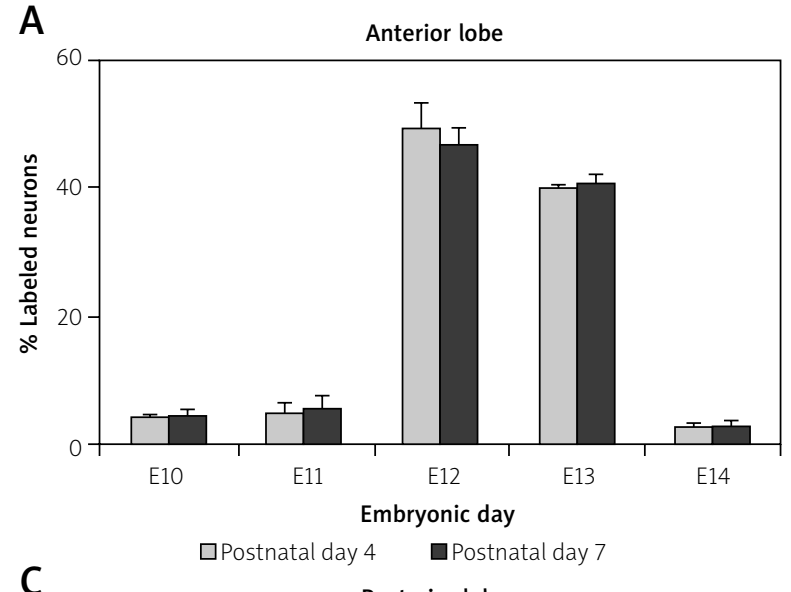

C

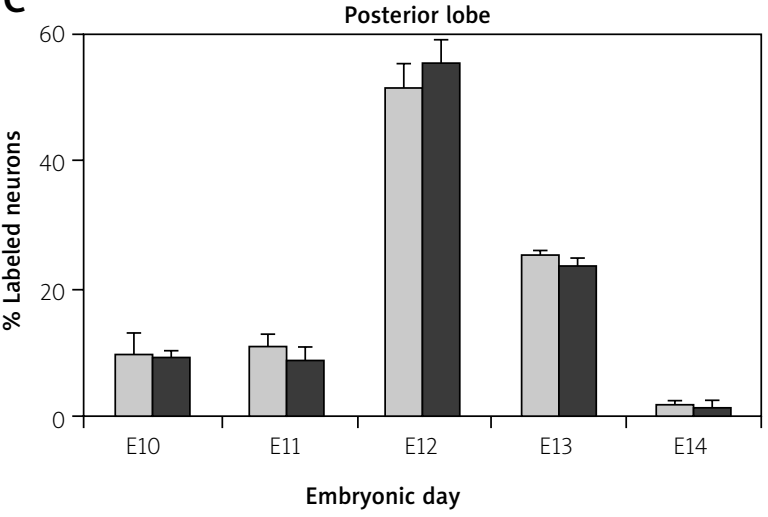

$\square$ Postnatal day $4 \quad \square$ Postnatal day 7
B
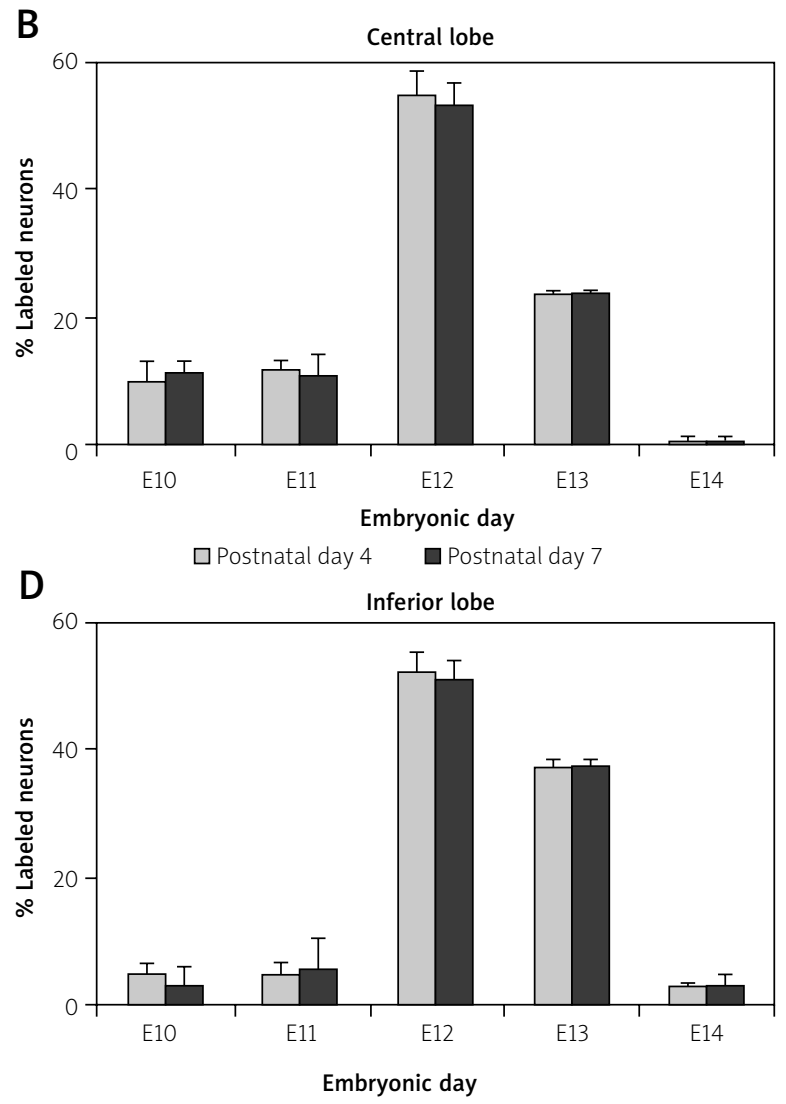

$\square$ Postnatal day $4 \quad \square$ Postnatal day 7

Fig. 3. Generative profiles for Purkinje cells within each cerebellar lobe examined. The inferred frequencies (ordinate) of newly generated neurons for P4 empty columns and P7 solid columns are plotted against the relative embryonic time-period (abscissa). Percentages of newborn Purkinje cells were determined by the rate of decline in $[3 \mathrm{H}] \mathrm{TdR}$-labeled cells at that time point.
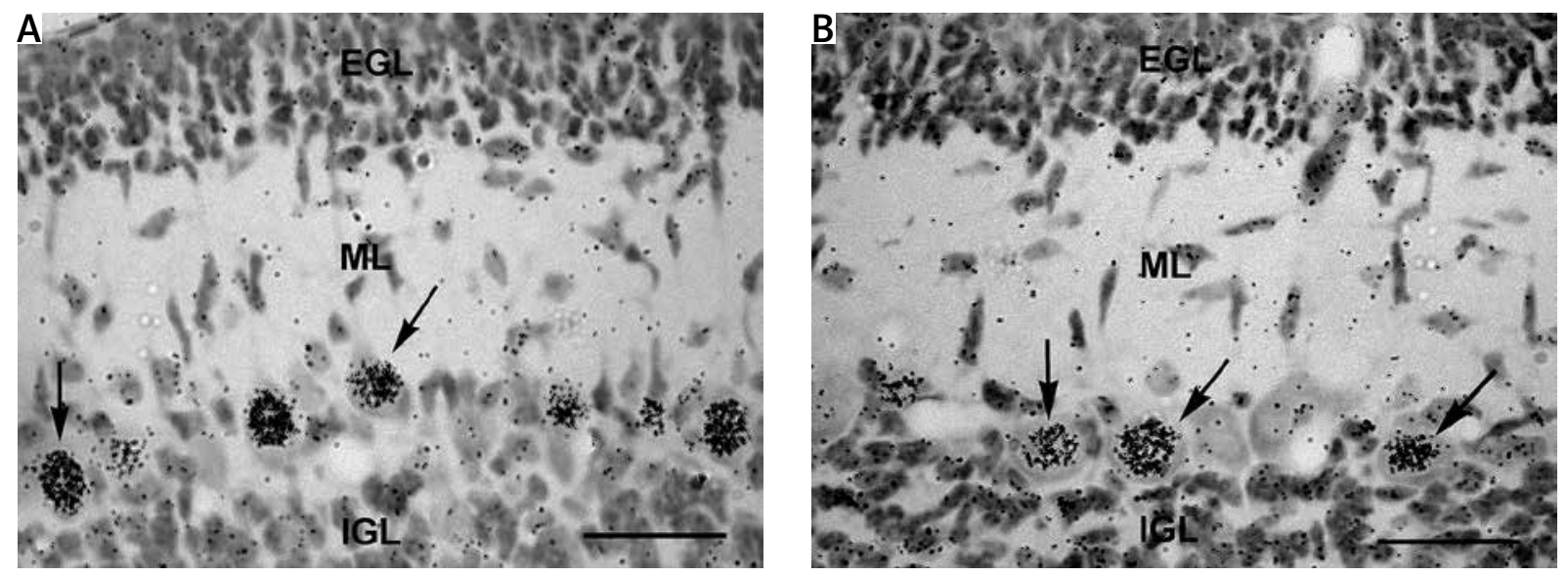

Fig. 4. Representative photomicrograph at the level of the lingula (posterior lobe) from mice exposed to $\left[{ }^{3} \mathrm{H}\right] \mathrm{TdR}$ on E12-13 (A) or on E13-14 (B) and killed at P7. Note that many Purkinje cells are labeled on E12-13, while on E13-14 the percentage of tagged cells declines reflecting the production of postmitotic neurons by their precursor cells. EGL - external granular layer, $\mathrm{ML}$ - molecular layer, IGL - internal granular layer. Arrows show examples of Purkinje cell labeled. Scale bars: $30 \mu \mathrm{m}$. 
man primates [34]. In mice, this event has been analyzed with contradictory results [5,14,22]. The current study reveals that in mice collected at P2 or at P12, no tyrosine hydroxylase-reactive cells with signs of apoptosis were found in the SNc. We do not know the reasons for these discrepancies but they may derive from biological differences among the mice strains studied, e.g. Lieb et al. [22] utilized CBA/J, Blum [5] used F2 littermates from a C57Bl/6 X 129 cross breeding, and $C 57 / \mathrm{bl}$ and $C D-1$ are used by JacksonLewis et al. [14]. BALB/c, C57BL/6 and B6CBA-A ${ }^{\mathrm{w}-\mathrm{j} / \mathrm{A}}$ hybrid stock are used in the present work.

From the present results, it is proposed that the naturally occurring DA-neuron apoptosis in the early postnatal life is an event that might be restricted to certain strains of mice. Another possibility is that the natural loss of DA cells occurs in all strains of mice but neurons die in some of these strains through a nonapoptotic mechanism. In this regard, there is evidence indicating that the nature of cell death in the SNc of the weaver homozygotes is not apoptotic $[33,35]$. This fact may be relevant to the pathogenesis of neurodegenerative diseases such as Parkinson's disease, in which the role of apoptosis has been questioned [41].

\section{Apoptotic natural cell death in PCs}

We show that PCS apoptosis occurs within the first postnatal week. Our data demonstrate that the most important number of apoptotic PCs was seen in the central lobe; this was followed by the posterior and anterior lobes and then by the inferior lobe. In addition, the estimated values of active caspase-3-immunoreactive PCs was lower than that of TUNEL positives nuclei, at all cerebellar cortex lobes examined. These results are in agreement with the findings from other investigations, which have shown that caspase-3 activation occurs early in the course of apoptosis and precedes DNA fragmentation $[9,32,45]$. Moreover, at the time of degeneration, we did not observe any differences in the cytoarchitecture of the cerebellar cortex at the light microscopic level, which suggests that the migration and settling of postmitotic PCs in the Purkinje cell layer was normal.

Generative timetables of PCs were inferred at the four, previously indicated, lobes through the anteroposterior axis of the cerebellar cortex. Our basic information is that the onset of PCs neurogenesis, its pattern of peaks and valleys, and its total span were close between P4 and P7. The experiments using ${ }^{3}[\mathrm{H}] \mathrm{TdR}$ autoradiography were designed to answer the question of whether the PCs apoptosis in the early postnatal period is related to neurogenetic patterns. If apoptosis of PCs is random across age, there should be no significant differences in the neurogenesis of PCs between P4 and P7. On the other hand, if apoptosis is systematic across age, the neurogenetic patterns of PCs should be different at P4 with respect to P7. The data reported here support the first possibility; no divergences were seen in PCs time-of-origin profiles. To our knowledge, this is the first report that links PCs neurogenetic timetables with the naturally occurring neuronal death of these macroneurons.

This report indicates that the times of origin for a given PC may not predispose it to start a developmental program of cell death. The same may occur in other neurons of the cerebellar system, which would ensure the organization and refinement of corticonuclear circuits. In this way, there is evidence showing climbing-fiber elimination [12] and loss of young granule cells [24] in the developing cerebellum. Moreover, alteration of basal neuron death in the human cerebellar system may be involved in sudden unexplained perinatal death; previous studies have found defects in both PCs and inferior olivary nuclei neurons in victims of sudden intrauterine unexplained death and sudden infant death syndromes [21].

\section{Acknowledgments}

The author is very grateful to Drs. Shirley A. Bayer and Bernardino Ghetti for providing B6CBA-A $\mathrm{A}^{\mathrm{w}-\mathrm{j}} / \mathrm{A}$ hybrid stock mice.

\section{Disclosure}

Author reports no conflict of interest.

\section{References}

1. Altman J, Bayer SA. Development of the Cerebellar System: In Relation to its Evolution, Structure and Functions. CRC Press, Inc., Boca Raton 1997.

2. Ashwell K. Microglia and cell death in the developing mouse cerebellum. Dev Brain Res 1990; 55: 219-230.

3. Barde YA. Trophic factors and neuronal survival. Neuron 1989; 2: 1525-1534.

4. Bayer SA, Altman J. Directions in neurogenetic gradients and patterns of anatomical connections in the telencephalon. Prog Neurobiol 1987; 29: 57-106. 
5. Blum M. A null mutation in TGF- $\alpha$ leads to a reduction in midbrain dopaminergic neurons in the substantia nigra. Nature Neurosci 1998; 1: 374-377.

6. Burke RE. Ontogenic cell death in the nigrostriatal system. Cell Tissue Res 2004; 318: 63-72.

7. Clarke PGH. Neuronal death in the development of the vertebrate nervous system. Trends Neurosci 1985; 8: 345-349.

8. Collo G, Cavalleri L, Spano P. Structural plasticity in mesencephalic dopaminergic neurons produced by drugs of abuse: critical role of BDNF and dopamine. Front Pharmacol 2014; 5 259.

9. Davoli MA, Fourtounis J, Tam J, Xanthoudakis S, Nichoson D, Robertson GS, Ng GY, Xu D. Immunohistochemical and biochemical assessment of caspase-3 activation and DNA fragmentation following transient focal ischemia in the rat. Neuroscience 2002; 115: 125-136

10. Dekkers MP, Nikoletopoulou V, Barde YA. Cell biology in neuroscience: death of developing neurons: new insights and implications for connectivity. J Cell Biol 2013; 203: 385-393.

11. Dikranian K. Ishimaru MJ, Tenkova T, Labruyere J, Qin YQ, Ikonomidou C. Olney JW. Apoptosis in the in vivo mammalian forebrain. Neurobiol Dis 2011; 8: 359-379.

12. Hashimoto K, Kano M. Functional differentiation of the multiple climbing fiber inputs during synapse elimination in the developing cerebellum. Neuron 2003; 381: 785-796.

13. Hsu SM, Soban E. Color modification of diaminobenzidine (DAB) precipitation by metallic ions and its application for double immunohistochemistry. J Histochem Cytochem 1982; 30 1079-1082.

14. Jackson-Lewis V, Vila M, Djaldetti R, Guegan C, Liberatore G, Liu J, O’Malley K, Burke RE, Przedborski S. Development cell death in dopaminergic neurons of the substantia nigra of mice. J Comp Neurol 2000; 424: 476-488.

15. Janec E, Burke RE. Naturally occurring cell death during postnatal development of the substantia nigra of the rat. Mol Cell Neurosci 1993; 4: 30-35.

16. Jankowski J, Miething A, Schilling K, Baader SL. Physiological Purkinje cell death is spatiotemporally organized in the developing mouse cerebellum. Cerebellum 2009; 8: 277-290.

17. Jankowski J, Miething A, Schilling K, Oberdick J, Baader SL. Cell death as a regulator of cerebellar histogenesis and compartmentation. Cerebellum 2011; 10: 373-392.

18. Kalinichenko SG, Matveeva NY. Morphological characteristics of apoptosis and its significance in neurogenesis. Neurosci Behavi Physiol 2008; 38: 333-344.

19. Kitao Y, Hashimoto K, Matsuyama T, Iso H, Tamatani T, Hori O, Stern DM, Kano M, Ozawa K, Ogawa S. ORP150/HSP12A regulates Purkinje cell survival: a role for endoplasmic reticulum stress in cerebellar development. J Neurosci 2004; 24: 1486-1496.

20. Kholodilov N, Yarygina O, Oo TF, Zhang H, Sulzer D, Dauer W, Burke RE. Regulation of the development of mesencephalic dopaminergic systems by the selective expression of glial cel line-derived neurotrophic factor in their targets. J Neurosci 2004; 24: 3136-3146.

21. Lavezzi AM, Corna MF, Repetti ML, Matturri L. Cerebellar Purkinje cell vulnerability to prenatal nicotine exposure in sudden unexplained perinatal death. Folia Neuropathol 2013; 51: 290301.

22. Lieb K, Andersen C, Lazarov N, Zienecker R, Urban I, Reisert I, Pilgrim C. Pre- and postnatal development of dopaminergic neuron numbers in the male and female mouse midbrain. Dev Brain Res 1996; 94: 37-43.

23. Linden R. The survival of developing neurons: a review of afferent control. Neuroscience 1994; 58: 671-682.

24. Lossi L, Mioletti S, Merighi A. Synapse-independent and synapsedependent apoptosis of cerebellar granule cells in postnatal rabbits occur at two subsequent but partly overlapping developmental stages. Neuroscience 2002; 112: 509-523.

25. Lossi L, Gambino G. Apoptosis of the cerebellar neurons. Histol Histopathol 2008; 23: 367-380.

26. Madolosso SH, Pérez-Villegas EM, Armengol JA. Naturally occurring neuronal death during the postnatal development of Purkinje cells and their precerebellar afferent projections. Brain Res Rev 2005; 49: 267-279.

27. Martí J, Wills KW, Ghetti B, Bayer SA. Regional differences in the Purkinje cells settled pattern: a comparative autoradiographic study in control and homozygous weaver mice. Exp Neurol 2002; 175: 168-181.

28. Martí J, Wills KW, Ghetti B, Bayer SA. A combined immnunohistochemical and autoradiographic method to detect midbrain dopaminergic neurons and determine their time of origin. Brain Res Protoc 2002; 9: 197-205.

29. Martí J, Santa-Cruz MC, Bayer SA, Ghetti B, Hervás JP. Purkinje cell age-distribution in fissures and in foliar crowns: a comparative study in the weaver cerebellum. Brain Struct Funct 2007; 212: 347-357.

30. Martí J, Santa-Cruz MC, Bayer SA, Ghetti B, Hervás JP. Generation and survival of midbrain dopaminergic neurons in weaver mice. Int J Dev Neurosci 2007; 25: 299-307.

31. Martí J, Santa-Cruz MC, Molina V, Serra R, Bayer SA, Ghetti B, Hervás JP. Regional differences in the vulnerability of substantia nigra dopaminergic neurons in weaver mice. Acta Neurobiol Exp 2009; 69: 198-206.

32. Mellios K, Zacharaki T, Sophou S, Latsari M, Antonopoulus J, Dinopoulus A, Parnavelas JG, Dori I. Natural and lesion-induced apoptosis in the rat striatum during development. Brain Res 2009; 1252: 30-44.

33. Migheli A, Piva R, Wei J, Attanasio A, Casolino S, Hodes ME, Dlouhy SR, Bayer SA, Ghetti B. Diverse cell death pathways result from a single missense mutation in weaver mice. Am J Pathol 1997; 151: 1629-1638.

34. Morrow BA, Roth RH, Redmond DE, Sladek JR, Elsworth JD. Apoptotic natural cell death in developing primate dopamine midbrain neurons occurs during a restricted period in the second trimester of gestation. Exp Neurol 2007; 204: 802-807.

35. Oo TF, Blazeski R, Harrison SM, Henchcliffe C, Mason CA, RofflerTarlov SK, Burke RE. Neuron death in the substantia nigra of weaver mouse occurs late in development and is not apoptotic. J Neurosci 1996; 16: 6134-6145.

36. Oo TF, Burke RE. The time course of developmental cell death in phenotypically defined dopaminergic neurons of the substantia nigra. Dev Brain Res 1997; 98: 191-196. 
37. Oo TF, Kholodilov N, Burke RE. Regulation of natural cell death in dopaminergic neurons of the substantia nigra by striatal glial cell line-derived neurotrophic factor in vivo. J Neurosci 2003; 23: 5141-5148.

38. Oo TF, Marchionini DM, Yarygina O, O'Leary PD, Hughes RA, Kholodilov N, Burke RE. Brain-derived neurotrophic factor regulates early postnatal developmental cell death of dopamine neurons of the substantianigra in vivo. Mol Cell Neurosci 2009 41: 440-447.

39. Oppenheim RW. Cell death during development of the nervous system. Ann Rev Neurosci 1991; 14: 453-501.

40. Oppenheim RW, Johnson JE. Programmed cell death and neurotrophic factors. In: Fundamental Neuroscience. Squire LR, Bloom FE, Mcconnel SK, Roberts JL, Spitzer NC, Zigmond JM (eds.). Elsevier Academic Press, San Diego 2003; 499-532.

41. Perry G, Nunomura A, Smith MA. A suicide note from Alzheimer disease neurons? Nat Med 1998; 4: 897-898.

42. Ries V, Cheng H-C, Baohan A, Kareva T, Oo TF, Rzhetskaya M, Bland RJ, During MJ, Kholodilov N, Burke RE. Regulation of the postnatal development of dopamine neurons of the substantia nigra in vivo by Akt/protein kinase B. J Neurochem 2009; 110: 23-33.

43. Sidman RL, Angevine JB, Taber-Pierce E. Atlas of the Mouse Brain and Spinal cord. Harvard University Press, Cambridge 1971.

44. Sulzer D, Surmeier DJ. Neuronal vulnerability, pathogenesis and Parkinson's disease. Mov Disord 2013; 28: 715-724.

45. Zacharaki T, Sophou S, Giannakopoulou A, Dinopoulus A, Antonopoulus J, Parnavelas JG, Dori I. Natural and lesion-induced apoptosis in the dorsal lateral geniculate nucleus during development. Brain Res 2010; 1344: 62-76. 